\title{
Editorial: International Society for Microbial Electrochemistry and Technology: Outputs From the 2018 Regional Meetings
}

\author{
Sarah M. Glaven ${ }^{1 *}$, Eileen Yu ${ }^{2}$, Jeffrey A. Gralnick ${ }^{3}$, Chi Ho Chan ${ }^{3}$, Srikanth Mutnuri ${ }^{4}$ and \\ Uwe Schröder ${ }^{5}$ \\ ${ }^{1}$ Naval Research Laboratory, Washington, DC, United States, ${ }^{2}$ School of Chemical Engineering and Advanced Materials, \\ Newcastle University, Newcastle upon Tyne, United Kingdom, ${ }^{3}$ BioTechnology Institute, University of Minnesota, St. Paul, \\ MN, United States, ${ }^{4}$ Applied Environmental Biotechnology Laboratory, Department of Biological Sciences, BITS Pilani K. K. \\ Birla Goa, Sancoale, India, ${ }^{5}$ Institute of Environmental and Sustainable Chemistry, Technische Universität Braunschweig, \\ Braunschweig, Germany
}

Keywords: microbial electrochemical technologies (MET), electromicrobiology, International Society for Microbial Electrochemistry and Technologies, microbial electrochemistry, electroactive bacteria

\section{Editorial on the Research Topic}

International Society for Microbial Electrochemistry and Technology: Outputs From the 2018 Regional Meetings

\section{OPEN ACCESS}

Edited by:

Pierangela Cristiani,

Ricerca Sul Sistema Energetico, Italy

Reviewed by:

Mirella Di Lorenzo,

University of Bath, United Kingdom

${ }^{*}$ Correspondence:

Sarah M. Glaven sarah.glaven@nrl.navy.mil

Specialty section: This article was submitted to Bioenergy and Biofuels, a section of the journal Frontiers in Energy Research

Received: 31 March 2020 Accepted: 28 April 2020

Published: 29 May 2020

Citation:

Glaven SM, Yu E, Gralnick JA, Chan $\mathrm{CH}$, Mutnuri S and Schröder U (2020) Editorial: International Society

for Microbial Electrochemistry and Technology: Outputs From the 2018

Regional Meetings.

Front. Energy Res. 8:91.

doi: 10.3389/fenrg.2020.00091
The International Society for Microbial Electrochemistry and Technology (ISMET) is the premier scientific society for all research involving microorganisms and electron exchange. Founded in 2011, ISMET is a highly interdisciplinary community of researchers ranging in expertise from fundamental microbiology and molecular genetics to electrochemistry and engineering. ISMET scientists study the complex interactions between living microbial cells and conductive surfaces. They leverage their understanding of the unique ability of some microorganisms to perform extracellular electron transfer (EET) to develop novel, sustainable processes and applications in biotechnology. New applications are sprouting up in areas such as microbial bioelectronics and new investigations have shown that electroactive bacteria can even be found in the human gut microbiome (Light et al., 2018). These new investigations and technologies reflect the fact that ISMET is more relevant than ever.

The term "microbial electrochemical technology" is built into the ISMET name, but what does it mean? According to Schroder et al. (2015), microbial electrochemical technologies (METs) are "applications or processes that utilize the electrochemical interaction of microbes and electrodes." The observation of bacteria interacting electrochemically with an electrode was first made over 100 years ago (Potter, 1911). Within the last 20 years what was a phenomenological observation has been put to technological use. METs have been developed for alternative energy production, wastewater treatment, and even biofuels production through the process of microbial electrosynthesis. An attractive aspect of METs is the fact that they enable carbon cycling; simple organic molecules in the sediment can be captured as biomass and electricity on anodes, and $\mathrm{CO}_{2}$ can be captured using the reducing power of an electrode at the cathode back into products or electricity from renewable sources.

The underlying molecular pathways and processes that result in EET in electroactive bacteria has been heavily studied in attempts to improve the efficiency and productivity of METs. Genetic engineering has been used to determine the molecular underpinnings responsible for carrying charge between cells and extracellular electron acceptors of the two model EET organisms, 
Geobacter sulfurreducens and Shewanella oneidensis. Researchers that study EET in the absence of an electrode or technological application, such as direct interspecies electron transfer, sometimes refer to their field as electromicrobiology, but much crossover exists and electromicrobiology is inherent to research conducted by the ISMET community. From a purely ecological perspective, the study of METs can inform our understanding of which bacteria connect with and communicate to metals and minerals in the environment, or to each other as part of the biogeochemical cycle.

The regional meeting special collection represents the spectrum of ISMET research occurring globally in both academic and government laboratories. The ISMET currently represents three broad geographical regions: ISMET North America (NA), ISMET Europe (EU), and ISMET Asia-Pacific (AP). A large, international meeting is held every other year to bring as much of the community together as possible. In between, regional ISMET meetings are held that highlight the work of talented postdocs and graduate students and feature innovative new concepts in METs. In 2018, the three regional meetings were held in Newcastle, United Kingdom (EU-ISMET September 1214), St. Paul, Minnesota, USA (October 10-12, NA-ISMET), and Goa, India (November 13-16, AP-ISMET). Each meeting had its own focus; from applied uses of bioelectrochemical systems in Newcastle, to fundamental microbiology and electrochemistry in Minnesota, to wastewater treatment in Goa. Research articles span from characterization of new electroactive bacteria (Onderko et al.) to the effect of electrode topography on biofilm formation (Moß et al.), to the growing area of electrofermentation (Joshi J. et al.; Rosa et al.) and effective methods for wastewater treatment (Sugioka et al.). Summaries of all 2018 ISMET regional meetings and information on upcoming meetings can be found at www.is-met.org.

The EU-ISMET meeting was hosted at Newcastle University in Newcastle upon Tyne, UK, a city that boasts the invention of the first microbial fuel cell (MFC) by Potter (1911). EUISMET researchers continue to lead the way in the application of METs for microbial electrosynthesis, bioremediation and water treatment. The regional meeting special collection captures just some of this exciting work. An emphasis on detection and remediation of water contaminants is highlighted in the work of Olias et al. and Mani et al., respectively, for using electrodes for atrazine detection and azo-dye remediation. Following on this theme, new technologies using floating MFCs to monitor wastewater while simultaneously harvesting energy are described by Cristiani et al. METs are typically based on cost-effective graphitic materials, the properties and characteristics of which are described by Roubaud et al. and Pötschke et al. One limiting factor in microbial fuel cells is the reaction rate at the cathode. EU-ISMET researchers are working to solve this problem using novel ideas. For example, Izadi et al. showed how acidophilic iron-oxidizing bacteria could be used as biocathode catalysts. Ramírez-Moreno et al. compared different approaches for cathodes used in desalination reactors, a growing application area for METs. We also saw exciting articles on engineered living electronic materials and their (You et al.).
The NA-ISMET meeting in St. Paul, Minnesota, USA, was hosted by a lively group of ISMET researchers from the University of Minnesota and focused primarily on fundamental molecular biology and biochemistry of EET. The articles published as part of this special collection reflect a focus on basic research and invite the reader to learn about topics ranging from the discovery and characterization of new EET organisms (Jangir et al., Ortiz-Medina and Call, and Onderko et al.), to the evolutionary relationship among cellular redox carriers (Campbell et al.). EET is a redox balancing act and papers captured here explore the importance of considering how different routes for electron exchange affect METs (Joshi K. et al.; Duhl and TerAvest). Cellular structures, known in S. oneidensis as outer membrane extensions, may aid in long range electron transfer (Chong et al.) and were shown here to be activated by cell surface attachment.

In Goa, the AP-ISMET community is focused on bioelectrochemical (and electrochemical) approaches for decentralized sanitation. The meeting took place at the Birla Institute of Science and Technology (BITS), Pilani, Goa, India. The BITS Pilani campus boasts both a small and large scale demonstration site for treatment of wastewater using constructed wetlands coupled to electrochemical chlorination. In this special collection, Talekar and Mutnuri describe membrane selection to maximize such systems. The vibrant research community of the AP-ISMET pushes the boundaries on how MET can be implemented to overcome issues such as ethanol fermentation, as described by Joshi J. et al.

An ongoing discussion within the ISMET community for both veteran scientists and those new to this area is the issue of nomenclature. As the ISMET community grows and becomes inclusive of additional disciplines (e.g., bioelectronics and synthetic biology), it is important to recognize terminology preferred by the established community in order to communicate our science and strengthen the existing lexicon. At each regional meeting this year the issue of ISMET nomenclature was highlighted as a top priority and culminated in a terminology survey. The survey considered terminology in four areas including The Field, The Process, The Technology, and The Microorganisms. The results of the survey are now shared on the ISMET website: https://is-met.org/ismet-terminology-survey/. ISMET researchers overwhelming preferred the term "microbial electrochemistry" to describe their field, and "extracellular electron transfer" to describe the process of electrons moving in and out of the cell. When microbes mediate the process of EET between the cell and a mineral or electrode, ISMET researchers preferred the term "microbial electrocatalysis." Researchers were asked which term they prefer to describe the systems that they use to study and innovate with electroactive bacteria. Over half of all respondents to the poll prefer to use the term "bioelectrochemical system." ISMET recognizes that the use of specific terms to define an individual's research is important and that terms are only useful if they are adopted by a field. Therefore, the results of this survey are not meant to be prescriptive but can serve as a reference point for those new to the ISMET community.

The ISMET community is strong and interest in microbial electrochemistry and electromicrobiology continue to attract 
talented scientists to explore the technological possibilities and basic science of this field. In the coming years, ISMET regional sections will expand to include Africa and South America. As we grow in new directions we consider what new tools must be brought to bear on our field in order to advance technology beyond what we have previously envisioned. This will include bringing in the tools of synthetic biology to specifically design and engineer electroactive organisms, standardization of labscale electrochemical reactors, and the ability to predict EET capabilities from newly sequenced genome and metagenome

\section{REFERENCES}

Light, S. H., Su, L., Rivera-Lugo, R., Cornejo, J. A., Louie, A., Iavarone, A. T., et al. (2018). A flavin-based extracellular electron transfer mechanism in diverse Gram-positive bacteria. Nature 562, 140-144. doi: 10.1038/s41586-018-0498-z

Potter, M. C. (1911). "Electrical effects accompanying the decomposition of organic compounds," in Proceedings of the Royal Society of London. Series B, Containing Papers of a Biological Character 84, 260-276.

Schroder, U., Harnisch, F., and Angenent, L. T. (2015). Microbial electrochemistry and technology: terminology and classification. Energy Environ. Sci. 8, 513-519. doi: 10.1039/C4EE03359K assemblies. In addition, we have only just scratch the surface on understanding natural mechanisms of EET and this work must continue in order to improve MET. We look forward to what comes next for this dynamic research area that truly is the definition of interdisciplinary.

\section{AUTHOR CONTRIBUTIONS}

All authors listed have made a substantial, direct and intellectual contribution to the work, and approved it for publication.

Conflict of Interest: The authors declare that the research was conducted in the absence of any commercial or financial relationships that could be construed as a potential conflict of interest.

Copyright (C) 2020 Glaven, Yu, Gralnick, Chan, Mutnuri and Schröder. This is an open-access article distributed under the terms of the Creative Commons Attribution License (CC BY). The use, distribution or reproduction in other forums is permitted, provided the original author(s) and the copyright owner(s) are credited and that the original publication in this journal is cited, in accordance with accepted academic practice. No use, distribution or reproduction is permitted which does not comply with these terms. 